\title{
Sources of Immunity to Error through Misidentification
}

\author{
Simon Prosser
}

In this paper I wish to draw attention to a feature of judgments expressible using indexical terms such as $I$, here and now and the significance this feature has for discussions of Immunity to Error through Misidentification (IEM). The feature in question is this: consider a subject who sincerely expresses a belief using an utterance of the form ' $\lambda$ is $F$ ', where ' $\lambda$ ' is an indexical term. Suppose ' $\lambda$ ' refers to some object $O$ (where an 'object' could be a place, time, or person as well as a physical object). Then the subject believes, of $O$, that it has the property $F$. Call this the stated belief. But the use of the indexical term ' $\lambda$ ' indicates that the subject also believes something else about $O$; something associated with the use of that indexical term. Call this the manifested belief. Someone who believes that the race starts now, for example, believes, of time $t$, that the race starts at $t$; but their use of 'now' indicates that they believe something else about $t$. Let $U$ be the utterance of the race starts now. Then the subject also believes, of $t$, that $t$ is simultaneous with $U$. For any indexical term there will be some such belief concerning the relation between the reference and the utterance token. As Prior (1959) pointed out, however, this would not account for the significance, for action, of believing that the race starts now; for one can correctly believe, at any time $t^{\prime}$, that $t$ is simultaneous with $U$, without this having any special significance for one's immediate actions. So perhaps the subject must also believe something else about $t$; most plausibly, something we might express by saying that $t$ is present. It is the latter kind of manifested belief that will be of interest to us. Similarly, someone who sincerely states that the race starts here believes, of a place $p$, that the race starts at $p$; but also believes that $p$ is where $I$ am (though I shall suggest below that this belief can take an unarticulated form, analogous to believing that a place is near or far). At any rate, I shall take it as a working hypothesis that all singular indexical judgments (other than those expressed 
using 'pure' demonstratives such as that) have some such associated manifested belief; and I shall consider the significance of this for IEM. Insofar as this hypothesis helps shed light on IEM, we can take this as weighing in favour of the hypothesis. ${ }^{1}$

An analogy with complex demonstratives (noun phrases of the form 'that $\varphi$ ', where the ' $\varphi$ ' component is called the nominal term) will be instructive in what follows. Someone who sincerely utters 'that $\varphi$ is $F$ believes, of an object $O$, that it is $F$ (the stated belief); but they also believe, of $O$, that it is a $\varphi$ (the manifested belief). Since either of these beliefs might be in error, an account of the epistemology of complex demonstrative judgments must take both kinds of error into account. The same, I suggest, is true for indexicals; in particular, we are unlikely to get a correct account of IEM in indexical judgments unless errors in both stated and manifested beliefs are allowed for. ${ }^{2}$

I shall proceed by focussing mainly on spatial indexicals because there are certain kinds of error that occur in perception-based spatial judgments that occur more rarely, if ever, for judgments about times or places. However I do think that the view that I shall develop applies equally to temporal and personal judgments; and I shall discuss these, including first-person judgments, toward the end of the paper.

\section{ERROR THROUGH MISIDENTIFICATION}

The phenomenon of Immunity to Error through Misidentification came to prominence through the work of Sydney Shoemaker (1968, 1970), though Shoemaker notes that

\footnotetext{
${ }^{1}$ I give a more direct argument for this view of indexical beliefs, based on the problems associated with cognitive dynamics, in Prosser 2005.

2 Would the same apply to judgments expressed using proper names? Insofar as there is a property of being named Smith (or being Smith for short), then we can form complex demonstrative judgments of the form 'that Smith is $F$. The choice of words indicates that the subject believes that the person in question is a Smith, as well as being $F$. If the above claims about indexicals are correct then one might wonder if it would equally follow that judgments expressed as 'Smith is $F$ ' are epistemically equivalent to judgments of the form 'that Smith is $F$ '. I have two responses: firstly one might accept a theory of names as equivalent to complex demonstratives; indeed Tyler Burge (1973) put forward just such a theory. But, secondly, one can resist the claim that names are associated with properties in the same way that indexicals are. For any name $\mathrm{NN}$ the only associated property is being named $\mathcal{N} N$; whereas for an indexical term $\lambda$ the interesting associated property is not being named/referred to as $\lambda$ (which would only be true relative to an appropriate context anyway), but rather a quite different kind of property; one with a more direct significance for belief and action.
} 
the phenomenon was discussed briefly by Wittgenstein (1958). ${ }^{3}$ The original interest was in first-person judgments, but others (e.g. Evans 1982) have subsequently argued for versions of the phenomenon applying to judgments expressible using other indexical or demonstrative terms. IEM is a property of judgments (where a judgment is the formation of a belief or knowledge based on specific reasons and/or evidence); it is not a property of a specific belief per se. By 'error' I shall mean a judgment that produces a false belief. The essence of IEM is that although almost any judgment can be in error, some judgments are immune to certain kinds of error. Following James Pryor (1999) we can illustrate two slightly different varieties of error through misidentification using the following examples:

Example 1: Smith is in a hurry. You see someone who looks like Smith running by and looking flustered. You judge that Smith is in a hurry. But the person you see is not Smith, and in fact Smith is not in a hurry. Consequently your judgment is in error, and the source of the error is that you misidentified the person you saw.

Example 1 corresponds to what Pryor calls de re misidentification; its essential feature is that the subject's justification for believing that Smith is in a hurry rests on, or can be no better than, the subject's justification for believing an identity statement of the form 'that person $=$ Smith'.

Note that although one may sometimes go through a conscious train of thought in which one infers ' $a$ is $F$ ' from a perceptual judgment ' $b$ is $F$ combined with the belief ' $a=b$ ', error through misidentification can occur without any conscious inference being made. In example 1 the subject might for example have a noninferential capacity to recognise Smith through sight, and thus judges that Smith is in a hurry based on the visual experience without mediation by a judgment of identity. What matters is whether the subject's judgment would have been undermined if some such identity had fallen into doubt. ${ }^{4}$

\footnotetext{
3 Early discussions of IEM include Wittgenstein 1958 and Strawson 1966 (164-5). Following Shoemaker's (1968, 1970) classic papers the phenomenon was given further prominence by Gareth Evans (1982). More recent discussions include Campbell 1997, 1999a, 1999b, Pryor 1999, Coliva 2003, 2006, Recanati 2007 and Peacocke 2008, though this list is far from complete. The phenomenon has a significant role in a great many discussions of the first person.

${ }^{4}$ Cf. Coliva 2006.
} 
Example 2: The Skunk (Pryor 1999: 281). You smell a skunk-like odour and thus judge that there is a skunk in the garden. As a matter of fact this is true. You then see a small animal in the garden and judge that that is a skunk. However this is false; the animal you see is not a skunk and did not produce the odour.

Example 2 corresponds to what Pryor calls wh-misidentification (short for which-objectmisidentification). This differs from de re misidentification in the following way: in cases of de re misidentification the putative grounds for the judgment ' $a$ is $F$ may provide genuine grounds for a different de re judgment ' $b$ is $F$ ', but there is error through misidentification because $a \neq b$. In cases of wh-misidentification, by contrast, there are no genuine grounds for any de re judgment of the form ' $b$ is $F$ ', but at most genuine grounds for a judgment of the form $\exists x F x$ (e.g. 'there is a skunk in the garden'). In other words, whereas in cases of de re misidentification the subject may be in a position to correctly judge, of some object, that it is $F$ but goes wrong with respect to which object this is taken to be, in cases of wh-misidentification the subject is at most in a position to correctly judge that something is $F$ and then goes wrong with respect to which object is taken to be $F$.

Pryor's distinction is an important one, but for present purposes I want to gather both kinds of error together under the heading of error through misidentification (EM) in order to distinguish EM from a different phenomenon that I shall call error through misclassification (EMC). The difference between de re and wh-misidentification should not be overstated; as Annalisa Coliva (2006: 414) points out, they are both cases in which a judgment would be undermined if an identity came into question, even though the identities in question might not involve the same kinds of concepts. In the first case the relevant identity would involve only de re concepts, as in 'that person $=$ Smith'. In the second case, by contrast, one side of the identity may involve descriptive content, as in 'that $=$ the creature responsible for the smell in the garden'. ${ }^{5}$

\footnotetext{
5 One might go further and hold that the descriptive content can be used to produce a de re concept using Kaplan's (1978, 1989a, 1989b) 'dthat' operator, to some extent undermining Pryor's distinction. Coliva (2006: 414) seems to have sympathy for such an approach; Pryor (1999: 282n) explicitly rejects it. It suffices for present purposes, however, to emphasise the sense in which there is a broadly similar structure to the epistemological situation in both kinds of case.

Here I ignore the fact the Pryor's skunk example allows for the possibility that there is more than one skunk. I think that the definition of EM could be amended to allow for this by replacing the notion of identity with the notion of set membership, but I shall not develop this here. Coliva (in correspondence), on the other hand, resists assimilating the multiple skunk case to cases of EM.
} 
The common factor in all cases of EM can be described in a slightly different way. In both of Pryor's cases a predicate ('is in a hurry' or 'is a skunk') is applied on perceptual grounds. In both cases there is some object (the hurrying person, the smelly skunk) that is the causal source of the information that leads to the application of the predicate. Call this the source object. Moreover in both cases the predicate is applied to an object (Smith, or the perceived animal). Call this the target object. But in both cases the source object is not identical with the target object, and that is why an error occurs. So we should expect that a judgment is immune to error through misidentification in just those cases where the source object and the target object cannot differ.

\section{IEM AND DEMONSTRATIVES}

Perception-based demonstrative judgments are often claimed to possess IEM (see for example Evans 1982, Campbell 1997, 1999a). There is a plausible reason for this. To take an extreme example, when one hears a sound and judges that is the sound of an oboe, the very same causal impacts on one's auditory apparatus allow one to judge what kind of sound it is and to know which sound is in question. ${ }^{6}$ The source object and the target object cannot fail to be the same sound; and consequently, although one's judgment might be in error it cannot be in error through misidentification.

Some visual demonstrative judgments may well possess IEM for the same reason. In particular, as Campbell $(1997,1999 a)$ has argued, judgments about the location of a visually perceived object arguably cannot be in error through misidentification; for although, due to a refractive illusion (such as a mirage) one might be mistaken as to the location of the object, there seems no room for the information by which one judges the location of the object to have come from a different object (Campbell argues that this is because the visual system binds together different information about an object (colour, shape etc.) by virtue of spatial location; the location is thus fundamental in individuating the object).

If this analysis of the two cases just described is correct then it is literally impossible for the source object and the target object to differ. Such judgments would thus

\footnotetext{
${ }^{6}$ A similar example is mentioned by Matthen (2006: 207).
} 
possess what Shoemaker (1970) called logical IEM. Other demonstrative judgments, on the other hand, may possess only what Shoemaker called de facto IEM; error through misidentification is impossible under normal circumstances, but might occur when conditions are exceptional. Thus for example, a vision-based judgment concerning the colour of a perceived object will normally possess IEM because the very same light, reflected by the object, at once allows one to determine the colour of the object and yet is also essential to one's knowledge of which object is in question (assuming one can only identify the object through sight). But in exceptional circumstances this IEM can fail, as in Campbell's (1997: 70) example of a transparent (or translucent) object seen in front of a yellow background, resulting in an erroneous judgment that the object is yellow (this counts as a misidentification because one's perception would put one in a position to correctly judge that something is yellow, yet the yellow object is not the target object). In what follows I shall assume that some judgments are indeed logically immune to error through misidentification. If, however, it turns out that there is no such phenomenon as logical IEM, and that at most a judgment can possess a strong de facto IEM, this will not greatly affect the argument.

What I mainly wish to draw attention to here is the mechanism described above, present in perceptual demonstrative judgments, by which the source object and the target object can be held together, resulting in IEM. This is not a new thought (Evans (1982) suggested something broadly similar). Neither is it a new thought that, as I shall argue below, the kind of IEM found in first-person judgments, as well as many 'here' and 'now'-judgments, derives from a different source. Indeed Shoemaker (1968: 5589) hinted at something along those lines, suggesting that the kind of IEM possessed by demonstrative judgments is of a different kind to that possessed by the first person, emphasising the importance of the fact that 'I' has its reference constrained by a token-reflexive rule in a way that 'that' does not. What will be new, however, is what I shall say about the role of the manifested belief in an indexical judgment.

\section{ERROR THROUGH MISGLASSIFICATION}

There is a common use of the word 'identification' to mean something like 'classification'. Thus when one sees what is in fact a buzzard and judges it to be a falcon, one can be said to have misidentified it. This is a quite different kind of 
'misidentification' from the one relevant to IEM; so to avoid confusion I shall call it misclassification, and speak of judgments as being in, or immune to, error through misclassification (EMC and IEMC respectively).

Although EM and EMC are clearly very different phenomena, both can result in a singular term being used in error where a different singular term would have been correct. In a familiar example of EM, I mistake your reflection in a mirror for mine and say 'your pants are on fire' when I should instead have said 'my pants are on fire'. In an example of EMC, I say 'that falcon is graceful' when I should instead have said 'that buzzard is graceful'. I thus use the singular term 'that falcon' when I should have said 'that buzzard'. A further example of EMC occurs when the subject says 'he' instead of 'she'. In all cases of EMC it is the manifested belief, rather than the stated belief, that is in error.

\section{ERRORS IN COMPLEX DEMONSTRATIVE JUDGMENTS}

I am going to draw an analogy between indexical judgments and complex demonstrative judgments, so I shall first discuss the latter in more detail. As mentioned above, a judgment of the form 'that $\varphi$ is $F$ is susceptible to two kinds of error: errors in the stated belief (the predicate 'is $F$ ' is in error), and errors in the manifested belief (the nominal term ' $\varphi$ ' is in error). Now, there is much controversy concerning whether a complex demonstrative 'that $\varphi$ ' can designate something that is not a $\varphi$. Some philosophers (e.g. Schiffer (1981), Perry (1997)) hold that the nominal term plays a pragmatic role in directing the audience's attention to the intended reference but does not contribute to the truth conditions of the sentence; the complex demonstrative contributes only its reference. Lepore and Ludwig (2000) and King (2001) argue against this view and in favour of the view that a complex demonstrative is a kind of quantifier. Some other philosophers (e.g. Kaplan (1978, 1989, 1989a), McGinn (1981), Peacocke (1981), Davies (1982), Recanati (1993), Richard (1993), Braun (1994), Borg (2000)), claim that the reference of 'that $\varphi$ ' must always be a $\varphi$; if one tries to demonstrate something that is not a $\varphi$ using the expression 'that $\varphi$ ' one might fail to demonstrate anything at all (it is as though one had used a simple demonstrative 'that' while pointing in the wrong direction). According to Lepore and Ludwig (2000), 
by contrast, 'that $\varphi$ ' refers to the intended reference but if the intended reference is not a $\varphi$ then the statement 'that $\varphi$ is $F$ is false (even if the intended reference is $F$ ). According to Schiffer (1981), Perry (1997), Corazza (2002) and (for slightly different reasons) Dever (2001), on the other hand, 'that $\varphi$ ' picks out the intended reference and if the intended reference is $F$ then 'that $\varphi$ is $F$ ' is true even if the intended reference is not a $\varphi$.

All of these claims, however, concern the semantic values (references and truth values) of linguistic utterances. No one doubts, I take it, that to make the judgment 'that $\varphi$ is $F$ ' of a thing that is $F$ but is not a $\varphi$ is to make some kind of error, and that to make the same judgment of a thing that is a $\varphi$ but is not $F$ is to make a different kind of error. Strictly speaking the claim that there are two distinct beliefs (stated and manifested) is not needed for present purposes; we just need the claim that there are two kinds of error. But it will be harmless to speak of the two kinds of belief in what follows.

Consider now an example of EMC. Jones sees a stranger waving a lottery ticket while drinking champagne and acting as if in celebration, and judges:

(1) That lottery winner is getting drunk

That the observed person was a lottery winner, and getting drunk, were both judged on the basis of perception. Suppose that the person in question did not win the lottery, and was merely drinking to ease the pain of losing yet again. (1) is thus in error through misclassification. Note, however, that (1) has at least de facto IEM; it would take a highly abnormal perceptual situation for (1) to be in error as a result of the source object differing from the target object, for the reasons given in section $3 .^{7}$

We can now consider a judgment that is immune to such errors (i.e. one that possesses IEMC). Nominal terms in complex demonstratives narrow down the candidates for the reference to varying degrees. The complex demonstrative 'that object' could be used without error to refer to any object; whereas 'that tall woman standing next to Barack Obama' could only be used without error to refer to a very

\footnotetext{
${ }^{7}$ A subsequent anaphoric use of 'that lottery winner' could result in error through misidentification (i.e. if the perceived person was falsely assumed to be the person who had been referred to in (1)). The claim that judgments like (1) are IEM applies only to perceptual demonstrative judgments where the object
} 
small range. In the extreme case the nominal term can limit the number of candidates within the relevant domain to one. There seems no good reason to deny this possibility; the fact that there happens to be just one $\varphi$ is no obstacle to it being referred to as 'that $\varphi$ '.

Moreover there are cases in which it is known to the subject that there is just one $\varphi$. In such cases there are judgments that the subject can make without perceiving the object. $^{8}$ For example, in the UK National Lottery anyone who picks the winning combination of numbers wins the lottery, and the prize is shared if there is more than one winner. When the draw is made the organisers know which combinations of numbers have been picked and by how many people, but do not know who bought the tickets carrying those numbers (the winners must subsequently make themselves known). Once the numbers have been drawn, however, it is customary for the lottery organisers to announce how many winners there are that week, even though their identities are unknown. Suppose that Jones heard an announcement on the radio that exactly one winning ticket had been sold that week. Based on a general knowledge of human nature, Jones now judges:

(2) That lottery winner will be celebrating tonight

Since no mention of any individual was made on the radio - the announcer merely stated how many winning tickets there were - Jones's thought would not be anaphoric. ${ }^{9}$ Now, (2) could be in error, but not though misclassification; there could not be an individual referred to by (2) who was not a lottery winner. (2) thus possesses IEMC.

As it happens (2) also possesses IEM; because Jones ascribed the predicate 'will be celebrating tonight' purely on the basis of knowledge about the likely behaviour of lottery winners, there is no possibility of the source object and target object being distinct (strictly speaking there is no source object). This, however, is a special case; when the predication is grounded by perception, error through misidentification can

referred to is not identified by independent means such as memory. I'm grateful to Annalisa Coliva for pointing out this possibility.

${ }^{8}$ Jeffrey C. King (2001) argues for this conclusion at some length. I do not have the space to discuss King's arguments in detail here and I shall take no view on his conclusions about when and if complex demonstratives directly refer or rigidly designate.

${ }^{9}$ Perhaps (2) could equally be expressed using Kaplan's (1978, 1989a, 1989b) 'dthat' operator, as in 'dthat (the lottery winner) will be celebrating tonight'. 
normally occur. Suppose for example that some time after hearing the radio announcement Jones sees an expensively dressed person being bundled in to a car by masked assailants. Jones leaps, incorrectly, to the following conclusion:

(3) That lottery winner is being kidnapped

Suppose that in (3) Jones is thinking of the lottery winner in the same way as in (2), trading on the knowledge that just one person won the lottery. Consequently there is no possibility of the person in question failing to be a lottery winner; (3) possesses IEMC. However (3) could be in error if the target object (the person referred to as 'that lottery winner') was not identical to the source object (the person who is seen being kidnapped). So (3) is susceptible to EM, despite being immune to EMC.

What we have, then, is that (1) possesses IEM but not IEMC, while (3) possesses IEMC but not IEM. (2) is a special case of a judgment that is both IEM and IEMC, but only because the predication in (2) is grounded in general knowledge rather than perception. Leaving aside such special cases, perception-based, non-anaphoric complex demonstrative judgments are normally either IEM or IEMC, but not both. The difference between the two kinds of immunity corresponds to a difference in the role of the nominal term ('lottery winner'). In (1), the nominal term is judged to apply; whereas in (3) the nominal term is stipulated to apply. ${ }^{10}$

\section{SPATIAL COMPLEX DEMONSTRATIVE JUDGMENTS}

Suppose that, for whatever reason, human beings frequently needed to talk about places that were close to the speaker (within about a metre, say) and to their left; and about places that were straight in front of the speaker and at middle distance, say about two metres away. Then we might have introduced the words 'closeleft' and 'midstraight', respectively, to capture those subject-relative locations; a place can be closeleft, just as it can be near or far. The associated complex demonstratives 'that

\footnotetext{
${ }^{10}$ If we regard the judgments expressible using 'that lottery winner' (where it is known that there is one lottery winner) as equivalent to some judgments expressible using 'the lottery winner' then the distinction made above between the two roles of the nominal term is very close to Keith Donnellan's (1966) distinction between referential and attributive uses of definite descriptions. Certainly Donnellan's
} 
closeleft place' and 'that midstraight place' could only be correctly used to refer to one specific region of space by a given subject at a given time.

Alternatively the words 'closeleft' and 'midstraight' could have been introduced with a different surface grammar such that instead of saying 'that closeleft place is $F$ ' or 'that midstraight place is $F$ 'we said 'it is $F$ closeleft' or 'it is $F$ midstraight'. The meaning and epistemological features of the judgments thus expressed would be exactly the same. ${ }^{11}$ When used in this way 'closeleft' and 'midstraight' are grammatically equivalent to indexical terms such as 'here' and 'now', differing only with respect to the location in the speaker's egocentric space to which they correspond (I shall set aside purely demonstrative uses of these words, such as when one points to a map and says 'the treasure is here').

Conversely, if 'closeleft' and 'midstraight'-judgments can have the concealed complex-demonstrative structure just described then there seems no obvious reason why 'here' and 'now' judgments should not be structured in the same way. If so, then a judgment expressed by 'it is $F$ here' could equally have been expressed in the form 'that $H$ place is $F$, where ' $H$ ' is a term of the same general kind as near or far, differing only in the egocentric relation that it captures. For some region of space $R$, to judge that $R$ is $H$ is to judge, at least implicitly, that one is located within $R$.

Perceived places or objects are usually experienced as having egocentric locations. In judging the egocentric location of something - judging that something is to the left, say - one does not have to compare its position with the perceived position and orientation of one's own body; indeed an invisible person would still see objects as egocentrically located in just the same way, despite seeing no body. Something can simply look, and be judged to be, to the left. This suggests that the egocentric content of spatial experience has a monadic form - objects appear as having properties such as to the left, near, far, closeleft, $H$ and so on, even though what makes it true that something is to the left is that it is to the left of the perceiving subject. In the content of experience, then, the perceiving subject very often figures only as an unarticulated constituent (Perry 1986; for similar claims see also Shoemaker 1994, p. 28 and Campbell's (1993, 1994, 1998) discussion of causal indexicality and his associated distinction between monadic

examples (such as 'Smith's murderer is insane') seem to exhibit a very similar pattern of IEM and IEMC.

11 There is no reason why a complex demonstrative should not have an unstructured linguistic form in natural language. The words 'she' and 'he', for example, might arguably be thought of as equivalent to 
and relational notions). It may be, then, that the best description of the content of some judgments is similarly monadic; one might judge that something is to the left without explicitly thinking about oneself, even though on reflection one would be aware that being to the left entails being in a certain spatial relation to oneself.

This claim is particularly plausible with respect to the equivalent temporal predicates such as past or future. Given the ongoing debate regarding the A and Btheories of time there is no current consensus about whether the properties picked out by these terms are monadic or relational; or, if they pick out relations, which relations these are. ${ }^{12}$ The equivalent first-person term (which, in effect, predicates the relation of identity with the subject) would have to be monadic, on pain of triviality. I shall say more about this below.

\section{ERRORS IN SPATIAL JUDGMENTS}

By analogy with other complex demonstrative judgments, we should expect judgments of the form 'that closeleft place is $F$, and hence judgments of the form 'it is $F$ closeleft', to possess either IEM or IEMC, but not normally both, depending on whether 'closeleft' is judged or stipulated. I shall argue that this is indeed the case. Consider first a case in which the nominal term is erroneously judged to apply. Sometimes one makes a judgment about a place by perceiving objects that are located at, or in a stable relation to, that place. Consider for example the well-known refractive illusion that makes a swimming pool look shallower than it really is. Someone who is aware of such illusions might be in a position to judge, of a location at the bottom of the pool:

(4) There is a lost piece of jewellery there

Given the subject's awareness of the likely presence of a refractive illusion, it seems most plausible to think that the place referred to by 'there' in (4) is the actual location of the jewellery rather than its 'virtual' location. An instruction given by the same subject to a colleague to 'swim down there and retrieve any lost jewellery that you find

the complex demonstratives 'that woman' and 'that man' respectively. Corazza 2002 makes precisely this claim. 
there' would clearly have been misunderstood if the colleague were to swim to the virtual location of the jewellery and return reporting that there was nothing there. The actual location of the jewellery, not the virtual location, would be the intended object of actions resulting from the judgment; this seems good enough reason to think that such judgments - at least when made by someone aware of the illusion - concern the actual location of the jewellery. ${ }^{13}$

If a subject who is aware of a likelihood of refractive illusions can make the kind of judgment just described, however, then there seems no reason why the same kind of judgment could not be made even by a subject unaware of the illusion. What characterises a judgment of this kind is that the subject's grasp of which location is in question derives from perceptual information, via objects perceived at, or in a stable relation to, the location. ${ }^{14}$

The subject who judged (4) would normally be in a position to judge whether the location in question appeared to be closeleft, or midstraight, etc. Suppose the subject did not suspect a refractive error, and possessed a quite specific term 'downleft' such that it appeared to the subject that the location of the jewellery had the property of being downleft. Then the subject could have made a judgment expressed as:

(5) There is a lost piece of jewellery downleft

If there were nonetheless a refractive illusion present, then the subject's judgment that the place was downleft (down and to the left) would be in error. This would be an error of misclassification, not misidentification. In judgments like (4) and (5), the source location and the target location cannot normally come apart; only unusual situations analogous to Campbell's transparent chair would allow error through misidentification of the place. So judgments like (5) possess at least de facto IEM, but do not possess IEMC.

As with previous examples of complex demonstrative judgments, however, the converse pattern of IEM and IEMC is also possible, and occurs when the nominal

12 I discuss the notion of unarticulated constituents in indexical thoughts in more detail in Prosser 2005 and specifically for temporal indexicals in Prosser 2006.

${ }^{13}$ See the exchange between John McDowell (1990) and Christopher Peacocke (1991) on this issue; I entirely agree with Peacocke.

${ }^{14}$ In judgment (4) the location could be, but need not be, thought of as the location of the perceived jewellery. But one need not always perceive an object at the relevant location for a judgment of this 
term is stipulated rather than judged. Consider, firstly, a subject in total darkness who judges:

(6) It is dark closeleft

In this situation the subject's only grasp of which location is in question is in virtue of the place being closeleft. ${ }^{15}$ The nominal term 'closeleft' is thus stipulated rather than judged, and the judgment possesses IEMC. But it does not possess IEM. Suppose a light is now seen, apparently coming from the place that is closeleft. The subject judges:

(7) There is a light closeleft

Due to a refractive illusion, however, the light did not come from the closeleft place. Consequently the source location was not closeleft even though the target location, by stipulation, was closeleft. Thus (7) is in error through misidentification of the location, even though it possesses IEMC.

One may sometimes be in a position to make either type of judgment in the same perceptual situation. The type of judgment depends on what the subject takes to determine the location that the judgment concerns; that is, by whether it concerns the place that is fixed by certain perceptual information, or whether it concerns the place that has the relevant egocentric property (e.g. closeleft).

\section{'HERE'-JUDGMENTS}

There is no difference in kind between judgments of the form 'it is $F$ closeleft' and judgments of the form 'it is $F$ here'. The only difference concerns the region of egocentric space associated with the correct use of the indexical term in question. A judgment correctly expressed using 'closeleft' concerns a region that is close and to the

general kind; one might, for example, judge that 'there is nothing there' when looking at a region of empty space bounded by some perceived objects.

15 Cf. Evans 1982, pp. 152-3, 161. 
left of the subject; a judgment correctly expressed using 'here' concerns a region that contains the subject.

For present purposes I am considering only uses of 'here' that are constrained by the standard token-reflexive rule; 'here' can also be used as a kind of pure demonstrative (as in 'the treasure is here', mentioned above), and perhaps in other ways, but I shall set aside these uses for present purposes. ${ }^{16}$ 'Here' may be used in referring to spatial regions of different sizes and shapes in different contexts, depending on the speaker's intentions. 'Here'-judgments are susceptible in principle to refractive illusions, just like 'closeleft'-judgments. A subject might, for example, see an object - a bee, say - that is two metres away but appears much closer due to an extreme refractive illusion. The subject, who treats 'here' as applying to a region with a boundary roughly one metre from the subject, might then judge:

(8) There is a bee here

This judgment could be of the 'stipulative' variety, such that 'here' necessarily refers to the region with a boundary one metre from the subject, in which case the judgment is in error through misidentification but possesses IEMC; or it could be of the 'judged' variety, such that 'here' refers to a region picked out perceptually and judged incorrectly to be $H$, in which case the judgment possesses IEM but is in error through misclassification. No doubt the stipulative variety of judgment is far common in practice; but the judged variety is at least possible in principle.

Gareth Evans seems not to have allowed for the possibility of refractive errors when he wrote:

It certainly appears that 'here'-Ideas tolerate no gap between information that it is $\mathrm{F}$ somewhere being received in the relevant ways and information that it is $\mathrm{F}$ here being so received; for example, if it seems to the subject that the property of places, being hot, is instantiated (simply by his feeling it to be hot) then it ipso facto seems to the subject that it is hot here (1982, pp. 182-3).

\footnotetext{
${ }^{16}$ For other uses see Smith 1989.
} 
Evans goes on to claim that 'here'-judgments are 'identification-free', which seems to be closely related to the notion that I have been capturing by saying that the source object and target object cannot differ. While Evans may well be correct in what he says about the example of feeling that 'it is hot here', notice that, like all his examples of IEM, it concerns a proximal sensory modality, i.e. one in which the sensory receptors (e.g. in the skin) are co-located with what they detect (the heat). Proximal perception literally leaves no gap for refractive or similar errors. But where there is distal perception such as vision (in which the perceived items are remote from the sensory apparatus), refractions and other such distortions can occur and the resulting 'here'-judgments are sometimes susceptible to error through misidentification.

Evans (1982, pp. 186-191) does discuss cases in which the subject is unknowingly wired-up to receive information from a distant location (e.g. by an unnoticed radio receiver in the subject's ear). He denies that such cases are counterexamples to IEM on the grounds that the information is not received in the normal way. This, however, strikes me as a rather arbitrary distinction. In any case, there seems nothing abnormal about the way in which information is received in the refractive visual cases discussed above; not unless 'normal' is taken in such a restrictive sense as to rule out refractions. This would trivialise the claim that 'here'-judgments possess IEM. Rather, we should say that there are cases (e.g. involving proximal perception) in which certain 'here' judgments possess de facto IEM, but this is not a characteristic of 'here'-judgments per se.

\section{AN OBJECTION}

At this point, however, I anticipate a troubling objection being raised regarding the possibility of a 'here'-judgment with a judged nominal term. According to this objection, 'here'-judgements are always stipulative; when one is subject to a refractive illusion one is always mistaken about the location of what one perceives. According to this view the errors that I have been describing as EMC are really cases of EM. One can indeed identify a place through perception but, where there is an illusion, rather than misascribing the predicate is $H^{\prime}$, one implicitly makes an incorrect identity judgment of the form 'that place = here' which leads one from a (possibly correct) judgment that could be expressed as 'that place is $F$ to a mistaken judgment it is $F$ 
here'. The challenge, for the position that I have advocated, is to make it convincing that the reference of 'here' can sometimes be determined perceptually - as the place that could equally have been referred to as 'that place' - rather than essentially being determined egocentrically as the place that is $H$.

Admittedly this line of objection has a strong intuitive pull. By way of reply, consider the following points, most of which are not individually decisive but I think they do add up to a plausible case:

(i) Perhaps the strongest case for believing that the reference of 'here' can be determined perceptually rather than egocentrically comes from the fact that one can keep track of a place perceptually while moving relative to it, requiring a shift in indexical term (from here to to the left for example). An argument can be given to the effect that in such cases the updating of the predicate term ' $F$ ' from 'it is $F$ here' to 'it is $F$ to the left' need not (and in some cases cannot) go via identities such as 'here $=$ that place' followed by 'that place $=$ to the left'. For this would require judging that place to have the property $H$ followed by the property to the left (how else could one judge the identities?), and once this much is conceded there is little motivation to deny that a 'here' (or other spatial indexical) judgment can have a judged nominal term. It is much more plausible that the nominal term is simply updated as one moves; one goes from judging that the perceived place has the property $H$ to believing that it has the property to the left while one moves, identifying the place in a constant, perceptual way throughout but changing the indexical term used to express judgments about it.

It is obvious that something of this kind happens with complex demonstratives; one goes from thinking 'that empty bottle is $F$ to 'that full bottle is $F^{\prime}$ while watching the bottle being filled. Much the same could therefore happen with the complex demonstratives formed using terms such as 'closeleft' and 'midstraight' and therefore ex hyothesi with their abbreviated equivalents (one goes from judging 'it is $F$ closeleft' to 'it is $F$ midstraight' while moving). If one accepts this much, it seems clear that the same could happen with familiar spatial indexical terms such as 'here' and 'to the left'. I have given these arguments in detail in Prosser 2005, so I shall not expand on them here. 
(ii) To the preceding point, we can add the following. Philosophers and psychologists are fond of speaking of 'egocentric space'. But to ascribe a position in egocentric space is just to ascribe an egocentric, relational property (such as being to the left). When one is in motion one is aware of the egocentric 'location' of a given objective location constantly changing. If egocentric locations were understood as literally locations this experience of motion would not be coherent, for locations cannot move relative to locations. Egocentric space should therefore be understood only as a 'space' of properties, a 'space' in the mathematician's sense. The experience of motion thus involves an awareness of a constant changing of the egocentric properties of locations and objects.

Hence when a subject in motion judges 'it is sunny up ahead', followed by 'it is sunny here', then 'it is sunny back there', all concerning the same, perceived place, the most plausible account of these judgments is the one according to which a series of different nominal terms is judged, rather than stipulated, to apply.

(iii) There certainly could be complex demonstratives such as 'that closeleft place', used in expressing judgments about a perceived place that the subject judges to be closeleft. Such judgments certainly could be expressed in the form it is $F$ closeleft'. So there certainly could be a corresponding use of here, differing only in that a place has to contain the subject, rather than being close and to the left of the subject, in order to be correctly referred to as here. So the only question is whether there are actual uses of 'here' of this kind. Even if there are not, however, the distinction between 'judged' and 'stipulated' nominal terms still helps clarify the nature of the 'here' judgments that actually do occur. The presence of a stipulated nominal term within the structure of the judgment will be relevant to a proper understanding of many cases of IEM (see below).

(iv) Jones arrives in a new place, sees the mountain scenery for the first time and exclaims:

(9) There are mountains here! 
Sometimes mountains are further away than they appear to be, even in the absence of refractive distortions. Suppose that (9) is in error for that reason. One possibility is that there are no mountains in the region that Jones refers to by 'here'. But it seems more plausible to say that the region that Jones refers to as 'here' does contain mountains but is larger than Jones had realised. If so, then (9) is not in error through misidentification, but through misclassification (it does not have the egocentric ' $H$ '-property that Jones judged it to have).

\section{TEMPORAL INDEXICAL JUDGMENTS}

We can now consider temporal indexicals. The manifested beliefs associated with temporal indexical judgments ascribe properties such as past, present and future to the times they concern. ${ }^{17}$ There is one disanalogy with the spatial case: whereas 'is $H^{\prime}$ might sometimes be understood as meaning 'is where I am now' (though I have suggested that it need not be), there is no directly equivalent reduction to the first person in the temporal case. The predicate 'is present' is not extensionally equivalent to 'is the time at which I am here', for I may be here at other times. If presentism is assumed then perhaps 'is present' could be reducible to 'is when I am' (i.e. the time at which I exist). But, otherwise, no first-person reduction seems possible.

I have acknowledged that for spatial indexicals the cases in which the nominal term is stipulated are more common than the cases in which it is judged. For 'now'judgments this is more extreme, to the extent that it could be doubted whether 'judged' cases ever occur in practice. Suppose, for example, that Jones sees a star explode but is unaware of the time that light takes to travel. Jones judges that:

(10) A star is exploding now

In fact the star exploded many years earlier. It would normally be implausible to claim that Jones's judgment concerned the time at which the perceived explosion really occurred. Rather, the error occurs because the source object (the time of the explosion) differs from the target object (the time correctly referred to as 'now'). Jones

\footnotetext{
${ }_{17}$ Quentin Smith (1990) has argued on independent grounds that 'now' statements ascribe presentness to times. I do not share his conclusions about the metaphysical nature of presentness.
} 
has thus made an error through misidentification. Judgments like (10) possess IEMC, but not IEM.

Most 'now'-judgments are like (10). Are there possible temporal indexical judgments wherein a time is judged, rather than stipulated, to be past, present, etc? One possible kind of case involves memory: one might make a judgment concerning an observed event, but one must then use a series of different indexicals to report one's judgment as time passes. One might keep track of the time at which the event occurred by being aware of its location in a series of events traced back from the present. As one subsequently reports the event at various times one goes from saying that the event is occurring now to saying just now, recently, some time ago, ages ago, and so on. One way to know which indexical term to use would be to be aware of the changing temporal properties of the event (properties such as pastness, presentness etc). In such a case, an error might occur through a misjudgment of the temporal property; one might, in effect, be mistaken about the exact relation between the source/target time and the present, without thereby misidentifying the time. So perhaps this is one way in which there could be temporal indexical judgments in which the nominal predicate is judged rather than stipulated.

\section{THE FIRST PERSON}

There is enough in common, at least superficially, between the words $I$, here and now to make it worth considering the hypothesis that first-person judgments have the same structure as 'here' and 'now'-judgments. I suggest that first-person judgments involve the tacit ascription of a nominal predicate 'is $\mathbf{~} \mathbf{\text { '; }}$ a judgment that ' $\mathrm{I}$ am $F$ ' is equivalent to a judgment of the form: 'that $\mathbf{\imath}$ is $F$. For a subject, $\mathrm{S}$, the predication 'is $\mathbf{l}$ ' is extensionally, but not psychologically, equivalent to 'is identical to S'. One can think of this by analogy with the spatial case; if one thinks of a place as here then this implicitly puts one in a certain relation to that place (the relation of being located there). Similarly if one thinks of a person as $I$ this implicitly puts one in a certain relation to that person (the relation of identity).

I have suggested that for spatial and temporal judgments the ascriptions of the relevant nominal terms can in principle be judged, even though they are more commonly stipulated. In the case of the first person, however, there is a reason to 
think that the nominal term can only ever be stipulated. Once one has made a firstperson judgment, all of one's subsequent first-person judgments are logically, and rationally, related to it. If one starts by judging 'I am $F$ ', one's subsequent judgment 'I am not $F^{\prime}$ directly contradicts the first judgment, and one would be irrational if one did not acknowledge the contradiction (if one underwent binary fission between the judgments (cf. Shoemaker 1970) then there would be no contradiction, but the subsequent judgment would be someone else's; the claim here concerns the judgments of a single subject). This need not be the case for 'here'; given the possibility that one moves between utterances of 'here', it can be intelligible to judge 'it is $F$ here' followed by 'it is not $F$ here'. It is hard to see how the logical relation between a single subject's 'I'-judgments could be accounted for if ' $\mathrm{I}$ '-judgments had judged nominal terms; it is not clear how the reference of 'I' could be guaranteed to remain the same for judgments made by the same person. It is not as though one has a way of constantly keeping track of oneself through perception. It is only the logical guarantee that whenever ' $\mathrm{l}$ ' is stipulated by a subject the reference of 'I' will always be that same subject that seems able to account for the logical and rational relations between different 'I' tokens.

Consequently, by analogy with judgments involving other indexicals with stipulated nominal terms, we should expect that first person judgments possess IEMC; and insofar as they possess IEM this is likely to be at most de facto IEM, not logical IEM, unless they have some further special feature that logically guarantees the identity of the source object and target object. This fits well with what many philosophers have come to believe about first-person judgments and IEM. Firstly consider the claim that first-person judgments possess IEMC. This fits well with the intuition that in many judgments about oneself one thinks about a person whose identity is not in question; one does not, as it were, identify a person then make a judgment that the person is me. Rather, there is a sense in which identification of oneself is prior to all observation (which is why one can still think about oneself even when in sensory deprivation). This perhaps corresponds to the claim that is sometimes made (deriving from Wittgenstein 1958 and discussed by Shoemaker (1968)) that there is a use of the first-person 'as subject' and a use of it 'as object'. The use of 'I' as subject comes about because a firstperson judgment, having a stipulated nominal term, does not require the identification of any person in perception.

By stipulating a nominal term one also constrains the routes by which information relevant to the judgment is standardly gathered. For example, stipulated 'closeleft'- 
judgments are based on information standardly selected from what we can call the closeleft channel (i.e. information that appears to derive from the place that is egocentrically closeleft, regardless of sensory modality and regardless of where the information actually derives from). Whenever the information that a predicate 'is $F$ ' is instantiated is received through that channel one is automatically in a position to judge that 'it is $F$ closeleft'. Much the same applies to the first-person. In stipulating 'is '' one fixes a standard channel from which information relevant to that judgment is selected. This channel consists in all the means by which one can gain information that directly concerns oneself; the standard forms of proprioception are the clearest examples, but perhaps introspection might involve something analogous. Thus when information that a predicate 'is $F$ ' is instantiated is received in the relevant ways - that is, through the relevant channel - it automatically puts one in a position to judge 'I am $F$ even though one's experience might not put one in a position to make a perceptual identification of a person. To use Evans's well-known example, if one feels, on the basis of proprioception, that someone's legs are crossed this immediately puts one in a position to judge that 'my legs are crossed'. In these circumstances no person is experienced 'as object'; one merely feels some crossed legs, and one thus encounters oneself only indirectly, 'as subject', by virtue of the channel through which the information is received. The stipulation of 'is l' thus accounts for the 'as subject'/'as object' distinction in first-person judgments (and indeed a corresponding distinction for spatial and temporal judgments can be explained in much the same way).

But what of the claim, made by Evans and many others, that judgments of the kind just described cannot be in error through misidentification? Discussions by Shoemaker and others have made it clear that such judgments possess at most de facto IEM, not logical IEM. There are always exotic scenarios in which error through misidentification can occur. One's proprioceptive judgments might, for example, come about through another person's body being 'wired up' to one's sensory apparatus; and judgments based on memory might in fact concern someone else's past (as described by Shoemaker (1970)). As it happens, the first-person channel is generally reliable; information received through proprioception, for example, normally does concern oneself because one's proprioceptive apparatus is hard-wired to one's own body. Hence the source object and target object are normally the same. But this is a contingency; it is not a logical feature of first-person judgments. The 
source of first-person IEM is the stipulation of 'is $\mathbf{~}$ ', which determines a reliable, albeit potentially fallible route for information about oneself. ${ }^{18}$

Judgments about oneself 'as object', by contrast, derive from channels other than those fixed by the stipulation of 'is l'; from seeing a reflection in a mirror, for example. In such cases error through misidentification occurs more easily, just because there is no hard-wiring of the kind that produces IEM in 'as subject' judgments.

\section{GONCLUSIONS}

I have identified two different kinds of immunity to error - IEM and IEMC - and have suggested that indexical judgments typically possess one but not the other, according to whether the nominal term associated with the indexical has the 'judged' or 'stipulated' role. Moreover I have suggested that while both kinds of role are possible, at least in principle, for spatial and temporal judgments, for first-person judgments the nominal term always has the stipulated role.

I have also identified two quite different sources of IEM. The first source is associated with perceptual demonstrative judgments, and occurs when the same information is used to ground a predication and also to identify the object. This occurs in those cases where the nominal term is judged, rather than stipulated. The second source of IEM is found in those cases in which the nominal term takes the stipulated role; the stipulation has the effect of establishing a standard 'channel' for information relevant to the judgment. Most of the time these channels are reliable; barring judgments about distant stars, information that seems to come directly from the present time normally does so; barring persons who undergo fission, or persons with sensory inputs hardwired to the bodies of others, and so on, information that seems to

\footnotetext{
${ }^{18}$ Many features of the account given here are consistent with the account put forward recently by François Recanati (2007), according to which information about oneself is sometimes acquired through the internal mode (which I take to be much the same as what I have called the 'channel' associated with the first person) and it is this that determines which person is relevant to the evaluation of the predicative content delivered in that mode (e.g. that someone's legs are crossed). Where I disagree with Recanati is in his claim that the 'implicitly de se' nature of these contents (i.e. the subject is not explicitly identified in the content) is what makes the judgments 'identification-free' and thus IEM. Recanati's idea is that because no subject is identified the subject cannot be misidentified. As I argue above, however, the IEM of these 'as subject' first-person judgments is only de facto and does not arise directly from a lack of representation of the subject, but rather because the stipulation of 'is ' ' (with resulting IEMC) ties the judgment to an information channel that (contingently) only provides information about the subject.
} 
come directly from oneself (through proprioception etc.) normally does so, and so on. So the stipulation of a nominal term is a source of IEM, though this is de facto rather than logical IEM.

Some of the distinctions made here are closely related to distinctions made by others. As noted above, for example, Shoemaker (1968: 558-9) suggested that perceptual demonstrative and indexical judgments possess different kinds of IEM. What I hope to have added is some explanation of these distinctions, and of the different kinds of immunity to error that can occur, by drawing attention to the presence of the manifested beliefs of the subject and the different epistemic roles that the nominal term can play. ${ }^{19}$

\section{REFERENCES}

Almog, J., Perry, J. and Wettstein, H. (eds.) (1989): Themes from Kaplan, Oxford: Oxford University Press.

Borg, E. (2000): 'Complex Demonstratives', Philosophical Studies 97, 229-49.

Braun, D. (1994): 'Structured Characters and Complex Demonstratives', Philosophical Studies 74, 193-219.

Burge, T. (1973): 'Reference and Proper Names', The Fournal of Philosophy 70, 425-39.

Campbell, J. (1993): 'The Role of Physical Objects in Spatial Thinking', in Eilan, McCarthy and Brewer 1993, 65-95.

Campbell, J. (1994): Past, Space and Self, Cambridge, MA/London: MIT Press/A Bradford Book.

Campbell, J. (1997): 'Sense, Reference and Selective Attention', Proceedings of the Aristotelian Society Supplementary Volume, 71, 55-98.

Campbell, J. (1998): 'Joint Attention and the First Person', in O’Hear 1998, 123-136.

Campbell, J. (1999a): 'Immunity to Error Through Misidentification and the Meaning of a Referring Term', Philosophical Topics, 26, 89-104.

\footnotetext{
${ }^{19}$ I would like to thank François Recanati and Annalisa Coliva for very helpful comments on earlier drafts of this paper, and Dilip Ninan, Derek Ball and other participants in a seminar in St Andrews for their comments during a discussion of the paper.
} 
Campbell, J. (1999b): 'Schizophrenia: The Space of Reasons and Thinking as a Motor Process', Monist, 82, 609-25.

Coliva, A. (2003): 'The First Person: Error through Misidentification, the Split between Speaker's and Semantic Reference, and the Real Guarantee'. The Fournal of Phlosophy, 100, 416-431.

Coliva, A. (2006): 'Error Through Misidentification: Some Varieties', Journal of Philosophy 103, 403-25.

Corazza, E. (2002): "She" and "He": Politically Correct Pronouns', Philosophical Studies 111, 173-196.

Davies, M. (1982): 'Individuation and the Semantics of Demonstratives', Fournal of Philosophical Logic, 11, 287-310.

Dever, J. (2001): 'Complex Demonstratives', Linguistics and Philosophy, 24, 271-330.

Donnellan, K. (1966): 'Reference and Definite Descriptions', Philosophical Review, 75, 281-304.

Eilan, N., McCarthy, R. and Brewer, B. (eds.) (1993): Spatial Representation, Oxford: Blackwell.

Evans, G. (1982): The Varieties of Reference, edited by J. McDowell, Oxford: Clarendon Press.

Kaplan, D. (1978): 'Dthat', in P. Cole (ed.) Syntax and Semantics, New York: Academic Press.

Kaplan, D. (1989): 'Demonstratives: An Essay on the Semantics, Logic, Metaphysics, and Epistemology of Demonstratives and other Indexicals', in Almog, Perry and Wettstein (eds.) 1989.

Kaplan, D. (1989a): 'Afterthoughts', in Almog, Perry and Wettstein (eds.) 1989.

King, J. G. (2001): Complex Demonstratives: A Quantificational Account, Cambridge, MA/London: MIT Press/A Bradford Book.

Lepore, E., and Ludwig, K. (2000): 'The Semantics and Pragmatics of Complex Demonstratives', Mind, 109, 199-240.

Matthen, M (2006): 'On Visual Experience of Objects: Comments on John Campbell's "Reference and Consciousness"', Philosophical Studies, 127, 195-220.

McGinn, G. (1981): 'The Mechanism of Reference', Synthese, 49, 157-86.

McDowell, J. (1990): 'Peacocke and Evans on Demonstrative Content', Mind, 99, 255266. 
O'Hear, A. (ed.) (1998): Current Issues in Philosophy of Mind; Royal Institute of Philosophy Supplement 43, Cambridge: Cambridge University Press.

Peacocke, C. (1981): 'Demonstrative Thought and Psychological Explanation', Synthese, 49, 187-217.

Peacocke, C. (1991): 'Demonstrative Content: A Reply to John McDowell', Mind, 100, 123-133.

Peacocke, C. (2008): Truly Understood, Oxford: Oxford University Press.

Perry, J. (1986): 'Thought Without Representation', Proceedings of the Aristotelian Society Supplementary Volume, 60, 137-51. Reprinted in Perry's The Problem of the Essential Indexical and Other Essays, Oxford: Oxford University Press, 1993. See also expanded edition: Stanford, CA: CSLI Publications, 2000.

Perry, J. (1997a): 'Indexicals and Demonstratives', in Bob Hale and Crispin Wright (eds.) A Companion to the Philosophy of Language, Oxford: Blackwell, 586-612.

Prior, A. N. (1959): 'Thank Goodness That's Over', Philosophy, 34, 12-17.

Prosser, S. (2005): 'Cognitive Dynamics and Indexicals', Mind \&̊ Language, 20, 369391.

Prosser, S. (2006): 'Temporal Metaphysics in Z-Land', Synthese, 149, 77-96.

Pryor, J. (1999): 'Immunity to Error through Misidentification', Philosophical Topics 26, 271-304.

Recanati, F. (1993): Direct Reference: From Language to Thought, Oxford: Blackwell.

Recanati, F. (2007): Perspectival Thought: A Plea for (Moderate) Relativism, Oxford: Oxford University Press.

Richard, M. (1993): 'Articulated Terms', in James Tomberlin (ed.) Philosophical Perspectives, 7, Language and Logic, Atascadero: Ridgeview, 207-30.

Schiffer, S. (1981): 'Indexicals and the Theory of Reference', Synthese, 57, 43-100.

Shoemaker, S. (1968): 'Self-Reference and Self-Awareness', Gournal of Philosophy, 65, 555-567.

Shoemaker, S. (1970): 'Persons and Their Pasts', American Philosophical Quarterly, 7, 269285.

Shoemaker, S. (1994): 'Phenomenal character', Noûs, 28, 21-38.

Smith, Q. (1989): 'The multiple uses of indexicals', Synthese 78, 167-191.

Smith, Q. (1990): 'Temporal Indexicals', Erkenntnis 32, 5-25.

Strawson, P. F. (1966): The Bounds of Sense, London: Methuen.

Wittgenstein, L. (1958): The Blue and Brown Books. Oxford: Blackwell. 